\section{THE DRAFT TRANSFER OF UNDERTAKINGS (PROTECTION OF EMPLOYMENT) REGULATIONS 2005}

The Department of Trade and Industry published a consultation paper and new draft Regulations to revise the Transfer of Undertakings (Protection of Employment) Regulations 1981 (TUPE) on March 15, 2005 (URN 05/926).

The government is keen, as it puts it, to "take the fear out of TUPE" by finding solutions to avoid uncertainty on outsourcing and changing employment conditions. This is the big opportunity to get TUPE right. A close examination of the draft Regulations reveals however, that all is far from crystal clear and much remains to be debated. The main thrust of the new Regulations is to improve business flexibility by extending coverage of TUPE in service contracting situations, such as cleaning, security and maintenance services, so as to make it clearer that TUPE applies in such situations; to increase the transparency of the transfer process by introducing a requirement on the old employer to notify the new employer of employment liabilities; to clarify the circumstances in which employers can lawfully make transfer related dismissals and agree transfer related changes to employment conditions; and, finally, to take up the option in Directive 98/50 for more flexibility in the application of TUPE to insolvency disposals to give a boost to the "rescue culture".

At the outset there is much to cheer. One example is relaxation of TUPE in insolvency cases. At present, 69 per cent of insolvencies result in an asset break up - the new provisions might just change that. Equally helpful is the provision for transferor notification to a transferee of employment liabilities that are going to pass on transfer.

Now to outsourcing. At first, a new supplementary definition of a transfer on service provision change is breathtakingly clear - as long as service activities cease by one person (transferor) and are taken up by a new person (transferee) and prior to the changeover there was an organised grouping of employees, the principal purpose of which was to carry out those activities, there will be a transfer. But this new definition is presently marred by proposed exceptions.

First, it will not apply if the client intends to use the contractor for a single specific event or task. So a conference project, for example, would be excluded. And this is so even if the client uses the contractor again. For, as the consultation paper says, this may be fortuitous - it may still not be intended that there be an ongoing relationship. Second, procurement of goods (as opposed to services) is outside the new definition. And, third, procurement of professional services (yet to be specified) is excluded. These loopholes will surely give rise to litigation and are ripe for exploitation.

\section{Articles \\ The criminal justice system's longstop: the work of the Criminal Cases Review Commission \\ Three Rivers: privilege re-assessed \\ Challenges for international and comparative law in the UK \\ Society and Institute News \\ Articles (cont'd) \\ The occlusion of opinion: incitement to religious hatred 20 \\ The Tsunami: a wake-up call for north and south 24}

Finally, will the new proposals make it easier for employers to vary employment terms or to dismiss in connection with a TUPE transfer? At the outset it should be noted that there is nothing in Directive 98/50, which allows change in this area. And ECJ case law also circumscribes room for manoeuvre. In making void agreements to vary where the transfer is the "principal" or "sole" reason the government has selected the case law test most favourable to employers from a number of conflicting decisions. But in proposing that a change may generally be justified by putting forward a general "economic, technical or organisational reason entailing changes in the workforce", the new Regulations arguably part company with European law (although the requirement that any qualifying contract variation must entail a change in the workforce will limit the use of this provision in practice).

On transfer connected dismissals, new Regulation 7 helpfully clarifies the legal test as to what is permissible. But the reader should be under no illusion that it does more; again, there is, for the legal reasons stated above, little room for the government actually to change the law in this area.

The new Regulations are the proverbial curate's egg partly very good, but in part bad. It is important also to conclude that it is foolish to read these new Regulations in isolation. Public sector transfers are governed by Cabinet Office guidance in 2000 and 2003, local government transfers by the Office of the Deputy Prime Minister Circular (03/2003). And pension transfer rules, imposing contribution obligations for the first time on private sector employers, apply under regulations made pursuant to quite separate legislation under the Pensions Act 2004 (the Transfer of Employment (Pension Protection) Regulations 2005). Notwithstanding new TUPE, therefore, it is unlikely that TUPE experts will go out of business.

\section{John McMullen}

Professor of Labour Law, University of Leeds, United Kingdom, a Member of the Council of ACAS and author of Business Transfers and Employee Rights (Butterworths). Professor McMullen addressed the IALS on this subject on June 22, 2005 